\title{
Nuclear DNA analysis of koilocytic and premalignant lesions of the uterine cervix
}

\author{
RHONA G HUGHES, WILLIAM A NEILL, MARY NORVAL
}

\begin{abstract}
Cervical biopsy samples were taken from 79 patients who had various grades of cervical intraepithelial neoplasia or who showed evidence, in the form of koilocytosis, of human papillomavirus infection of the uterine cervix and from 10 women with normal cervices. The DNA content of the cells in the samples was analysed by flow cytometry. Analysis of the data obtained showed that the biopsy samples from women with cervical intraepithelial neoplasia and human papillomavirus lesions contained significantly more dividing cells $(31.2 \%$ of cells from human papillomavirus lesions with no cervical intraepithelial neoplasia and $33.06 \%, 29.89 \%$, and $31 \cdot 76 \%$ of cells from cervical intraepithelial neoplasia grades I, II, and III, respectively) than those from women with normal cervices $(21 \cdot 6 \%)$. The proportion of aneuploid samples from the group who showed evidence of human papillomavirus infection only (18.2\%) did not differ significantly from the group with cervical intraepithelial neoplasia grade III $(21 \cdot 2 \%)$.

Aneuploidy and an increased rate of cellular proliferation are recognised characteristics of malignancy. These results therefore support the view that human papillomavirus plays an important part in the aetiology of cervical carcinoma and are relevant to the clinical management of patients.
\end{abstract}

\section{Introduction}

The association between infection of the lower genital tract by human papillomavirus and intraepithelial neoplasia has been recognised for some time, and an increasing body of evidence suggests that this association is causal rather than casual. ${ }^{1}$ The

\footnotetext{
Department of Bacteriology, University of Edinburgh Medical School, Edinburgh EH8 9AG

RHONA G HUGHES, MB, CHB, Melville Trust clinical research fellow

WILLIAM A NEILL, MPHIL, research technician

MARY NORVAL, PHD, lecturer

Correspondence to: Dr Hughes.
}

lesions caused by papillomaviruses tend to be persistent and are characterised by increased proliferative activity. These features, as well as the results of animal studies, ${ }^{2}$ make the viruses attractive candidates for playing a part in human carcinogenesis.

Most human cervical carcinomas contain aneuploid cell populations, ${ }^{3}$ and a variable proportion of cases of cervical intraepithelial neoplasia are also aneuploid. ${ }^{4}$ In addition, the number of proliferating cells in a tumour increases with increasing malignancy. ${ }^{5}$ Since the introduction of flow cytometry it has become possible to identify aneuploid populations with greater accuracy and to quantify the fraction of a cell population in each phase of the cell cycle. In this study we used an EPICS flow cytometer to examine both of these aspects in cervical intraepithelial neoplasia and in infection of the cervix by human papillomavirus.

\section{Patients and methods}

Patients-We studied 79 patients aged 22 to 47 referred to the Lothian area colposcopy clinic with abnormal cervical cytology or a clinically suspicious cervix. Ten women aged 25 to 43 who had a history of normal results of smears and who were undergoing minor gynaecological procedures were included as controls.

Biopsies-A cervical biopsy sample was taken from the transformation zone of each patient and control; all the samples from the patients came from areas shown to be abnormal by colposcopy. The specimen was snap frozen on dry ice and stored at $-80^{\circ} \mathrm{C}$ until processed further. A single $8 \mu \mathrm{m}$ cryostat section was taken from the centre of each specimen and prepared for routine histopathological examination with a conventional haematoxylin and eosin stain. Cervical intraepithelial neoplasia was classified according to recognised criteria. ${ }^{6}$ Koilocytes (balloon shaped cells with a perinuclear halo) were considered to be diagnostic of human papillomavirus infection. ${ }^{7}$ The remainder of the biopsy sample was then thawed, minced, and incubated in $3 \mathrm{ml} 0.5 \%$ solution of pepsin (Sigma) in $0.01 \mathrm{M}$ phosphate buffered saline, with the $\mathrm{pH}$ adjusted to 1.5 with hydrochloric acid, at $37^{\circ} \mathrm{C}$ for one hour. The supernatant was drawn off and centrifuged at $2000 \mathrm{~g}$ for 10 minutes, and the resultant pellet was washed in phosphate buffered saline and respun at $2000 \mathrm{~g}$ for 10 minutes.

Staining-The nuclear suspension was stained with a modified method of Deitch et al. ${ }^{8}$ The pellet was dispersed in $2 \mathrm{ml}$ solution containing $50 \mu \mathrm{g}$ propidium iodide (Sigma) per $\mathrm{ml}$ in $0.01 \mathrm{M}$ trometamol (TRIS) ( $\mathrm{pH} \mathrm{7.0}$ ) with $5 \mathrm{mM}$ magnesium chloride, $0: 1 \%$ Triton $\mathrm{X}-1 \mathrm{C0}$, and $15 \mu \mathrm{g}$ ribonuclease (Sigma) per $\mathrm{ml}$ and incubated at $4^{\circ} \mathrm{C}$ for one to 24 hours. The nuclei 
were then centrifuged at $2000 \mathrm{~g}$ for 10 minutes and resuspended in phosphate buffered saline.

Controls for flow cytometry-Red blood cells from chickens were run with each sample as an internal control, the DNA content of such cells being $35 \%$ of that of a human diploid cell. ${ }^{9}$ They were stained with the propidium iodide solution as described above. Human peripheral blood lymphocytes were stained and run with chicken red blood cells as an external control at the start of each run.

Flow cytometry-The flow cytometer used was an EPICS C (Coulter)
DNA index of 1 equalled the DNA content of a diploid cell. A sample wasp considered to contain an aneuploid component if the DNA index was less than 0.9 or greater than $1 \cdot 1$ or if it contained a main subsidiary peak that wasD distinct from the $G_{0} / G_{1}$ (diploid) and $G_{2}+M$ peaks. All four abnorma groups yielded some aneuploid samples, the proportion of aneuploid cells ranging from $14 \cdot 3 \%$ (cervical intraepithelial neoplasia grade I) to $21 \cdot 2 \%$ (grade III). Of the 15 aneuploid samples identified, six were hypodiploid (DNA index <0.9) and nine were hyperdiploid (DNA index $>1 \cdot 1$ ). The DNA index of hyperdiploid cell populations was always less than 1.5 .

Proportion of nuclei from cervical biopsy samples in various phases of cell cycle and number of samples containing aneuploid cells

\begin{tabular}{|c|c|c|c|c|c|}
\hline $\begin{array}{c}\text { Result of } \\
\text { histopathological examination }\end{array}$ & $\begin{array}{l}\text { No of samples suitable } \\
\text { for parametric analysis }\end{array}$ & $\begin{array}{c}\%(S D) \text { Of nuclei in } \\
\mathrm{S} \text { phase }\end{array}$ & $\begin{array}{c}\%(S D) \text { Of nuclei in } \\
S+G_{2}+M \text { phases }\end{array}$ & Significance & $\begin{array}{l}\text { No (\%) of samples containing } \\
\text { aneuploid cells }\end{array}$ \\
\hline $\begin{array}{l}\text { Normal } \\
\text { Koilocytosis alone } \\
\text { Cervical intraepithelial neoplasia: }\end{array}$ & $\begin{array}{l}10 / 10 \\
10 / 11\end{array}$ & $\begin{array}{l}11 \cdot 97(4 \cdot 00) \\
20.64(8 \cdot 62)\end{array}$ & $\begin{array}{l}21 \cdot 60(4 \cdot 51) \\
31 \cdot 20(8 \cdot 53)\end{array}$ & $p<0.05$ & $\begin{array}{l}0(0) \\
2(18)\end{array}$ \\
\hline $\begin{array}{l}\text { Grade I } \\
\text { Grade II } \\
\text { Grade III }\end{array}$ & $\begin{array}{l}14 / 14 \\
20 / 21 \\
31 / 33\end{array}$ & $\begin{array}{l}23 \cdot 25(9 \cdot 36) \\
19 \cdot 80(7 \cdot 74) \\
18 \cdot 27(5 \cdot 80)\end{array}$ & $\begin{array}{l}33 \cdot 06(8 \cdot 71) \\
29 \cdot 89(8 \cdot 39) \\
31 \cdot 76(8 \cdot 38)\end{array}$ & $\begin{array}{l}p<0.01 \\
p<0.01 \\
p<0.01\end{array}$ & $\begin{array}{l}2(14) \\
4(19) \\
7(21)\end{array}$ \\
\hline
\end{tabular}

*Comparison with normal group by Mann-Whitney U' test.

equipped with an argon ion laser that used $200 \mathrm{~mW}$ power and emitted light at $488 \mathrm{~nm}$. The nuclei were run at a rate of $150 /$ second until 20000 stained nuclei had been counted.

Analysis of data - The data obtained were subjected to parametric analysis with the EPICS PARA 1 program, which determined the proportion of nuclei in each phase of the cell cycle. The significance of the differences in each group compared with the control group was calculated with the Mann-Whitney U test.

\section{Results}

\section{CELL CYCLE ANALYSIS}

The table shows that of 89 cervical biopsy samples examined, 10 were classified by histopathological criteria as normal squamous epithelium, 11 as containing areas of koilocytosis without evidence of cervical intraepithelial neoplasia, and 68 as showing evidence of cervical intraepithelial neoplasia: 14 grade I, 21 grade II, and 33 grade III. Four specimens produced histograms on flow cytometry that, because of an abnormal distribution of DNA, were unsuitable for parametric analysis and were omitted from this part of the study.

The table also shows the proportion of cells in the $S$ phase (the phase of DNA synthesis) and in the $G_{2}$ (the phase after DNA synthesis) $+M$ (the phase of mitosis) phases of the cell cycle. The figure shows the data obtained from one biopsy sample.

Traditionally, studies of cellular proliferation have examined only the fraction of cells in the $S$ phase, as the cells in the $G_{2}+M$ phases could not be quantified by the uptake of tritiated thymidine. Two of us (RH and WN) analysed the histograms independently and found that calculating the total proportion of cells in the $S+G_{2}+M$ phases was less subject to variation among observers than calculating the proportion of cells in the $S$ phase alone, though as can be seen from the table the two measurements gave very similar results.

The fraction containing cells in the $S$ phase increased from $11.97 \%$ of the total in normal epithelium to $20.64 \%$ in epithelium containing koilocytes but no cervical intraepithelial neoplasia $(p<0.05)$. The samples from patients with cervical intraepithelial neoplasia all contained significantly more cells in the S. phase than those from the control group. There were no significant differences between the group with koilocytosis and the group with cervical intraepithelial neoplasia. When the $S$ and $G_{2}+M$ phases were considered together a similar pattern was seen. All four groups with abnormal samples (koilocytosis alone, cervical intraepithelial neoplasia grades I, II, and III) contained significantly more cells in the " $+G_{2}+M$ phases than the control samples but did not differ significantly from each other.

\section{ANEUPLOIDY}

The DNA index was calculated from the ratio between the chicken red blood cell and sample modal channel numbers versus the ratio between chicken red blood cell and lymphocyte modal channel numbers. Thus a

\section{Discussion}

Our analysis of cellular DNA content by flow cytometry shows̀ that normal cervical epithelium can be distinguished from epi thelium with koilocytosis (evidence of human papillomavirus infection) and with cervical intraepithelial neoplasia. Epitheliumw with koilocytosis or cervical intraepithelial neoplasia differed from normal epithelium in containing a larger proportion of proliferating

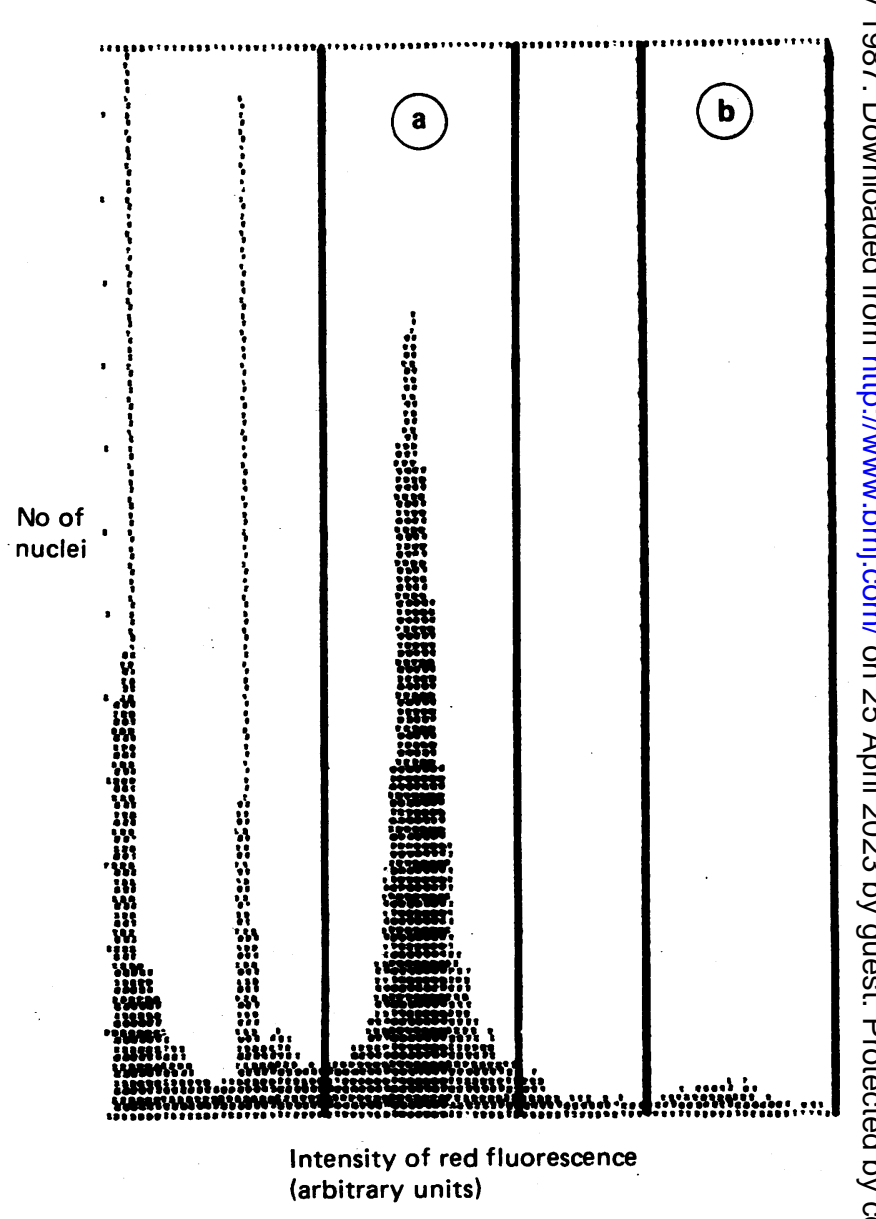

Result of flow cytometry of nuclear DNA from cervical biopsy. $G_{0} / G_{1}$ peak lie within set of cursors marked (a) and $G_{2}+M$ peak within cursors marked (b $S$ phase fraction lies between two sets of cursors, and chicken red blood cell nuclest form peak to left of (a). 
cells (cells in $S+G_{2}+M$ phases) and, in some cases, possessing an aneuploid component. In many systems aneuploidy and an increased rate of cellular proliferation are characteristics of malignancy.

It has been postulated that cells infected with papillomavirus initially behave as though stimulated by a non-specific mitogen and that in a semipermissive epithelium many cells remain in a prolonged $S$ or $\mathrm{G}_{2}$ phase. ${ }^{10}$ Reid proposed that cumulative mitotic errors in these stem cells might result in occasional chromosomal mutations spawning clones of aneuploid basal cells. ${ }^{11}$ By showing an increased proportion of cells in the $S+G_{2}+M$ phases in the koilocytic group our work supports this view. The samples from the cervical intraepithelial neoplasia grade II and III lesions contained a smaller proportion of proliferating cells than samples from the koilocytic and cervical intraepithelial neoplasia grade I lesions, though the difference was not significant. This fits Reid's hypothesis that the virus initially stimulates epithelial proliferation leading to arrest in the $S$ phase and the emergence of aneuploid populations.

In contrast with the work done by other groups ${ }^{4}{ }^{12}$ the prevalence of aneuploidy did not increase significantly with increasing severity of cervical intraepithelial neoplasia in this study. The proportion of samples containing aneuploid populations was essentially similar in the four abnormal groups, including the group with koilocytosis alone (range $14 \cdot 4 \%$ to $21 \cdot 2 \%$ ). To our knowledge this is the first published report of aneuploidy in "benign" human papillomavirus infection of the cervix, and it supports the hypothesis that human papillomavirus does have a central role in the aetiology of cervical carcinoma.

In addition, the implications for the management of patients with any evidence of cervical human papillomavirus infection or of cervical intraepithelial neoplasia grade I may be far reaching. In many centres these women are treated conservatively in the hope that the lesion will regress. It has been suggested that the clinical behaviour of lesions may be predicted on the basis of the degree of ploidy..$^{13}$ On the other hand, our data seem to indicate that so called benign human papillomavirus infections and cervical intraepithelial neoplasia grade III share similar patterns of DNA synthesis and thus should be treated identically.

We are grateful to Drs G E Smart and S Fletcher for enabling us to obtain biopsy material from patients and clinical information and for helpful discussions and to the staff of the Lothian area colposcopy clinic for their help. We thank the Cancer Research Campaign for funding this project and the Melville Trust for a clinical fellowship for RGH.

\section{References}

1 Anonymous. Genital warts, human papilloma viruses and cervical cancer [Editorial]. Lancet 1985;ii: $1045-6$.

2 Pfister H. Biology and biochemistry of papillomaviruses. Rev Physiol Biochem Pharmacol 1984;99:111-68.

3 Jakobsen A, Bichel P, Sell A. DNA distribution in biopsy specimens from human cervical carcinoma investigated by flow cytometry. Virchows Arch [Cell Pathol] 1979;29:337-42.

4 Jakobsen A, Kristensen PB, Poulsen HK. Flow cytometric classification of biopsy specimens from cervical intraepithelial neoplasia. Cytomeory 1983;4:166-9.

5 Laerum O, Farsuno T. Clinical application of flow cytometry: a review. Cytometry 1981;2:1-13.

6 Buckley CH, Butler EB, Fox H. Cervical intraepithelial neoplasia. F Clin Pathol 1982;35:1-13.

7 Fletcher S. Histopathology of papillomavirus infection of the cervix uteri: the history, taxonomy, nomenclature and reporting of koilocytic dysplasia. $f$ Clin Pathol 1983;36:616-24.

8 Deitch AD, Law H, White RD. A stable propidium iodide staining procedure for flow cytometry. f Histochem Cytochem 1982;30:967-72.

9 Vindelov LL, Christensen IJ, Nissen NI. Standardisation of high resolution flow cytometric DNA analysis by the simultaneous use of chicken and trout red blood cells as internal reference standards. Cytometry 1983;3:328-31.

10 Reid R, Stanhope CR, Herschman BR, Booth E, Phibbs GD, Smith JP. Genital warts and cervical cancer. I. Evidence of an association between subclinical papillomaviral infection and cervical malignancy. Cancer 1982;50:377-87.

11 Reid R. Genital warts and cervical cancer. II. Is human papillomavirus infection the rigger to cervical carcinogenesis? Gynecol Oncol 1983;15:239-52.

12 Reid R, Crum CP, Herschman BR, et al. Genital warts and cervical cancer. III. Subclinical papillomaviral infection and cervical neoplasia are linked by a spectrum of continuous morphologic and biologic change. Cancer 1984,53:943-53.

13 Fu YS, Reagan JW, Richart RM. Definition of precursors. Gynecol Oncol 1981;12:5220-31.

(Accepted 30 October 1986)

\section{YEARS AGO}

The tragedy at Cretingham will doubtless be followed by the thorough examination of the prisoner by the "Crown Referee in cases of supposed insanity." The facts are these: "Last Sunday, the Rev. E. G. Cooper cut the throat of the Rev. W. M. Farley, Vicar of Cretingham (Suffolk), whose curate he had been for some time. The unfortunate clergyman was 73 years of age, and the accused is a young man not much above 30. Mrs. Farley, the vicar's third wife, is in the prime of life. On Saturday she slept as usual at the foot of her husband's bed, he being an invalid. The curate, who resided in the same house, went to the bedroom door a little after midnight. The vicar, hearing a sound, aroused his wife, who allowed $\mathrm{Mr}$. Cooper to enter; whereupon the latter went up to the clergyman and cut his throat with a razor. It appears that he left the house, and that after his return Mrs. Farley said to him: "You don't know what you have done." Mr. Cooper did not reply. She then said: "Shall I write to your mother?" to which he only answered: "Oh, no." To the parish clerk, who on going to the vicarage said to him: "This is a sad affair," Mr. Cooper replied that it was. When asked if there was any cause for his conduct, he answered, in a low voice and with some hesitation: "No, no; I don't know that there was any." The clerk interrogated him further as to whether he had previously contemplated the act, to which he made answer: "Yes, yesterday I thought about it." When charged at Framlingham with the wilful murder of Mr. Farley, he said, "Isn't he alive?" and subsequently, "I am not aware that Mr. Farley is dead; I don't believe he is." At the inquest the prisoner kept his hat on till it was removed. He is said to have been bewildered at first, but afterwards to have appeared aware of the gravity of his position. The verdict was "Wilful murder."

It would be premature to offer any decided opinion as to the state of the prisoner's intellect. At the same time, there are strong reasons for supposing that the murder is the act of a lunatic. Of homicidal impulse, in the proper sense of the term, there is, indeed, no evidence. We suspect it will ultimately be proved that he was of feeble mind and decidedly peculiar. Some confused delusion may have sprung up, probably an exaggeration of the unpleasantness there had once been between the vicar and himself, and in the mental excitement consequent upon it-but without any adequate motive-he seems to have resolved, on the Saturday, to commit the fatal deed. It is stated that his bed was found much disarranged, as if he had been tossing about in it before he was able to carry out his intention.

Since the evidence given at the inquest, the Dover correspondent of the Daily Telegraph makes a statement, which, if confirmed, is of great importance. This is to the effect that Mr. Cooper was, from 1882 to 1885 , curate to the vicar of River and Guston at Dover; that, during the period mentioned, his conduct was at times very eccentric; and that, in consequence of his strange behaviour, he had to leave his duties in some haste. It is also alleged that he had sunstroke in India when very young, and it now appears that he was actually confined for some time in an asylum with acute homicidal mania, and that some years ago he was summarily dismissed from a school at Godalming (where he was assistant master) for a passionate attack on a pupil. That with such antecedents he should have been thought fit to perform the functions of the office of curate at Cretingham was scarcely complimentary to the intelligence of the parishioners. Mrs. Farley, indeed, asserts that she treated him in a maternal manner, "as he was but a boy, though upwards of thirty."

The foregoing observations are, of course, made on the supposition that the alleged improprieties between Mrs. Farley and Mr. Cooper are not confirmed so as to afford an adequate motive for the crime. (British Medical Fournal 1887;ii:780.)

Professor Grant, of the Observatory, Glasgow, speaks of the great heat during the week before last as phenomenal, and as prevailing "throughout the whole week with an intensity which, for the month of June, has not been paralleled during the last quarter of a century, and probably has been unsurpassed during a much longer period." The highest temperature was reached on the 25 th, when the maximum temperature in the shade was $82^{\circ} .7$, and the maximum in the sun was $133^{\circ} .2$. The lowest reading was on the 20 th, when it was $65^{\circ} .9$ in the shade, and $118^{\circ} .5$ in the sun. During three days of the week, 23rd, 24th, and 25 th, it was above $130^{\circ}$ in the sun. (British Medical Fournal 1887;ii:83.) 